\title{
STANCE OF INDONESIAN WRITERS IN JOURNAL ARTICLES
}

\author{
Yana Qomariana, Putu Lirishati Soetama \\ Udayana University \\ yana_qomariana@unud.ac.id, lirishati_soethama@unud.ac.id
}

\begin{abstract}
Stance refers to attitude, feelings, judgment or commitment of a speaker towards a proposition. A speaker employs certain linguistic features to express his stance including hedges, boosters, self-mentions and attitude markers. This research aims at analyzing stance of Indonesian writers in social and hard science journal articles written in English by examining the use of linguistic features employed as stance markers. This research applied descriptive qualititative method. Data was taken from Introduction part of 16 national journals written by Indonesian writers. The stance markers in data were identified and analyzed whether they represent approval of the writers. The research result shows that the writers of social science articles use more stance markers compared to those of hard science articles. Indonesian writers maintain the objectivity of academic writing as there was very limited use of self-mentions in the articles. The stance markers used by Indonesian writers represent the approval, disapproval or neutral type of stance.
\end{abstract}

Keywords: stance, Indonesian writers, journal articles

\section{INTRODUCTION}

Stance refers to "lexical or grammatical expression on attitude, feelings, appreciation, or commitment towards content of a proposition (Biber \& Finegan, 1998). According to this definition, the writers' stance can be observed through expressions selected in his statements. He can show agreement or disagreement towards a topic by employing one linguistic feature, such as 'agrees to' or 'on the opposite of'.

Stance has been a topic of interests of many research. Linguists have analyzed stances from verbal or written sources. Hyland (1998) wrote aspects of stances in conversations. The writers' stances are generally expressed clearer in written sources, including news articles or autobiographies. In these sources, stance markers can be observed through selected linguistic features.

Stance markers are also found in scientific papers; such papers that are known to be neutral have started changing its tradition. Hyland (2005) mentioned that in the last few decades academic writings have no longer maintained their characteristic as the objective writings which do not show any signs of the authors' subjectivity. Academic writings have changed to become the authors' persuasive effort of communicating his ideas to readers.

The pioneer of research on stance are Hyland (1998), Bermann (2002) and Dubois (2007). Starting from his writing that discussed features of hedges, Hyland has since written many aspects of stances from of verbal sources. Dubois (2007) enhances the relationship between the writers and their readers. He used the term stancetaker for writers who convey their position in their articles. Further, Dubois explains that a writer takes a stance through linguistic feature he selected. The use of stance markers selected by writers is an action of stancetaking (Thomson and Hunston, in Bahrami 2018). While Bermann (2002) analyzed written or verbal resources as discourse or text.

Chindamo (2012) provides summary of stance classification. There are three categories of stance, they are epistemic, affect and manner. Epistemic stance expresses the writers' degree of certainty towards a topic. Stance of affect is named for expression of feeling, mood, disposition attitude and feelings. The third category of stance refers to the writers' style of speaking. Stances can be expressed by employing lexico-grammatical features as stance markers including adverbs, modals, adjective or nouns. The writers' stance can be categorized into three types, they are supportive, disapprove or neutral (Tiang and Liang, 2014). The writers' judgment towards other writers' proposition can be observed by examining the tone of the stance markers that the writers' selected.

\section{MATERIALS AND METHOD}

This research employs descriptive qualitative method. The data was taken from Introduction part of 16 national journals in the field of economy, politics, electrical and computer science and agriculture. These journals were selected as representative of social science and hard science. The articles were written by Indonesian writers and were published in the last five years. 
This research is focused on the Introduction and Literature Review parts of journal articles based on the reason that these are parts that the writers review the previous research by using stance markers. Therefore, the parts were considered suitable to be data in this research.

In the next stage, stance markers in the form of hedges, boosters, attitude markers and selfmentions in the articles were identified and counted. As Introduction and Literature Review parts of the articles have variety in length, the stance markers are counted in terms of 1000 words. The figures of hedges, boosters, self-mentions and attitude markers were then are compared to see how often writers of social sciences articles employ the stance markers compared to the hard science. The statistical difference between the two types of articles was checked by using Chi-square test.

\section{RESULTS AND DISCUSSION}

The results and discussion are presented in three different sections. The first section discusses the frequency of hedges in social science and hard science article, the second part discusses frequency of boosters in social science and hard science article, the third part discusses frequency of self-mentions in social and hard science article, and the last part discusses the frequency of attitude markers in the data as well as analyzing the tone of stance markers.

\section{III.1 Hedges}

Hedges refers to linguistic features that show writers' uncertainty. It can also be mentioned as means to 'decrease epistemic commitment and expanding discursive space' (Aull and Lancaster, 2014). Hedges include modal verbs expresses probability (may, might, could), adverbs (generally, possibly, likely), verbs (suggest, indicates) (Hyland, 2005). Based on the data, more hedges are found in social sciences compared to hard science, as illustrated in Figure 1.

Figure 1 shows that writers of social science articles employ ore hedges. This agrees to findings of Hyland (1998) and Vatalla (2001)

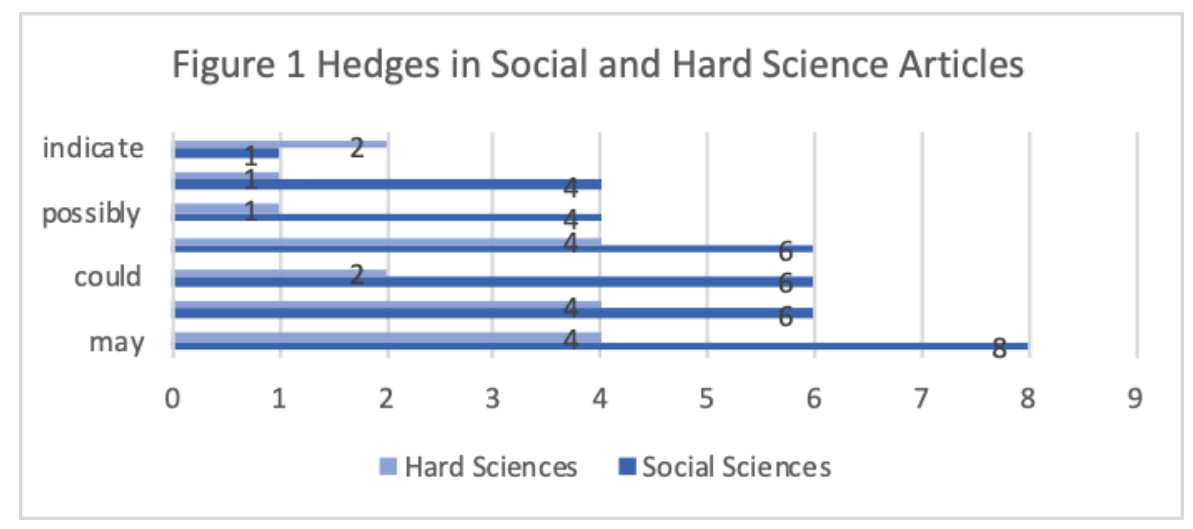

Several hedges used in social and hard science articles are provided below:

(I-1) On the other hand, the increase in loan losses is less likely to occur when the loan growth is caused by something other than a shift in the loan supply. (S10)

(I-2) Data from BIS indicate that the average credit growth for the non-financial sector in the G20 countries was $6.3 \%$, from 2008 to 2017. (S23)

(I-3) GWAS is often utilized when we are interested in finding out all the genomic regions that may control a specific role. (H4)

(I-4) The soil macronutrients indicated in a low content of $\mathrm{N}$ total (\%), Ca, and Mg. (H8)

The data above illustrates that hedges are used more frequently by writers of social science compared to writers of hard science. This is consistent with the previous study by Farrokhi \& Emami (2008). This finding shows that writers of social science expresse more uncertainties in their articles, while writers of hard science are more direct in expressing their judgment. Modal verbs are the most frequent hedge found in both social and hard science articles which express possibility of a phenomena to occur. Data (I-2) shows verb indicate that appeared in social sciences is used actively, while in hard science the verb is used in passive construction; in which in terms of information packaging, it shows that information at front of the sentence is considered more important. 


\section{III.2 Booster}

On the opposite of hedges, boosters are devices to show confidence of the writer. Boosters are usually found in the form of adverbs (absolutely, clearly, definitely, certainly, very, highly, obviously, really and the like), modals (must, will), verbs (demonstrate, show, find). Boosters found in the data are illustrated in Figure 2.

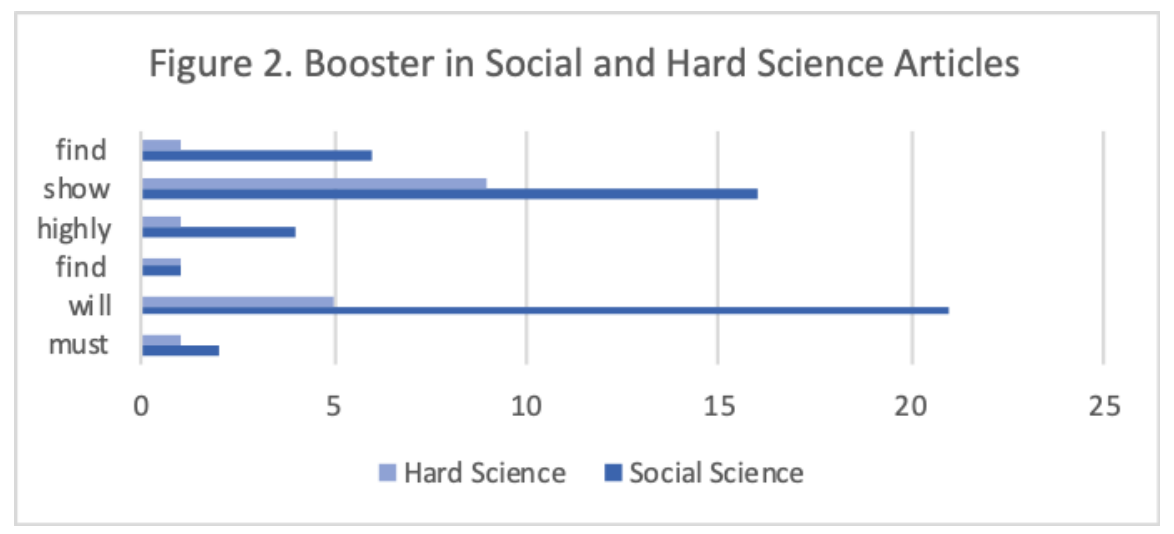

The figure above shows that similar to finding on hedges, writers of social science articles use more boosters in comparison with those of hard science articles. One reasonable rationale for this finding is that the writers of hard science articles maintain more objectivity of their articles.

The followings are several sentences taken from the data that contains booster.

(I-5) The banking sector is the most highly regulated sector in every country. (S9)

(I-6) Brand imagery shows the brand's ability to meet the psychological or social needs of customers.

(I-7) The phenotypic performances of 50 accessions of LG population showed abundance on morphological variation. (H12)

(I-8) Researcher must contend with the cofounding effects of both population and family structure. (H15)

All the boosters used in the sentences carry the function to improve the nature of quality being discussed in the sentences. In this case, the writers enhance his opportunities to underline the points he needs to deliver in his statements. In the data, boosters are found in the form of adverbs, verbs and modal verbs.

\section{III.3 Self-Mentions}

Self-mentions are the mention of the writer in the form of pronoun (I, we, our, us). This is the least stance markers used in the data. Based on the data, self-mention is only found once. Although it has been mentioned that academic articles have shown more of authors' subjectivity, majority of writers still maintain the objectivity of article by avoiding mentioning themselves as writers. The following sentence is taken from the data as the sample of sentence that include self-mention.

(I-9) We propose that the team monitoring is needed. (H23)

The self-mention strengthens the writers' position related with activity being carried in the topic of discussion. In the above sentence, the overt use of pronoun provides the entity who does the activity more emphasis on the pronoun as the executor of the mentioned activity.

\section{III.4 Attitude Markers}

Attitude markers show the writers' attitude on propositions, agreement, importance, obligation or frustration (Cazares-Cervantes, LaGue \& Dykeman (2019).). Linguistic features employed as notion of the writers' attitude are expressed by using various means, therefore, there is no standardized stance features applied to analyze this stance type. Attitude markers in social science and hard science articles are compared in terms of appearing token. The frequency of appearance of attitude marker in social and hard science articles are illustrated in Figure 3. 


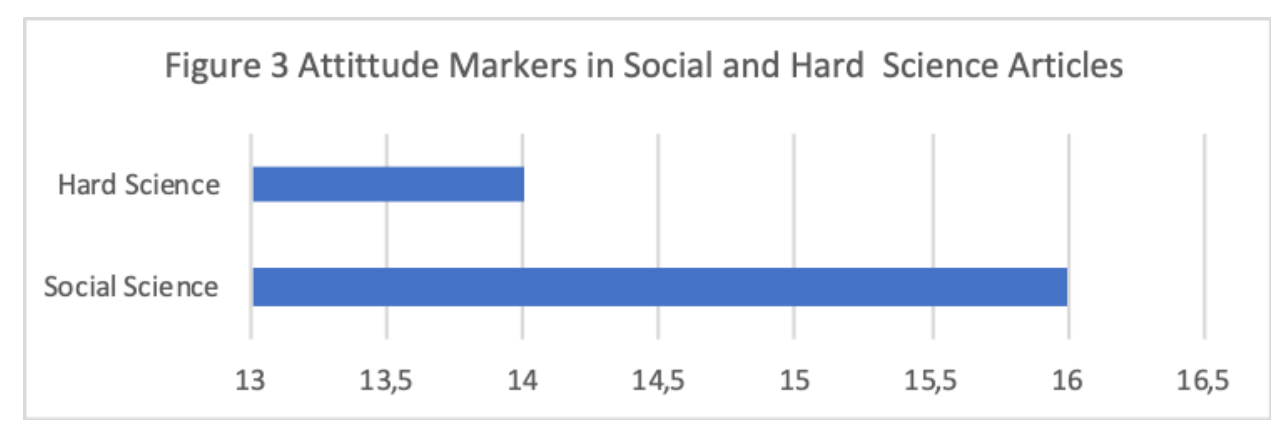

Based on Figure 3, it can be seen that attitude markers appear in social science articles doubles the size of ones found in hard science. This is in line with the appearance of hedges and boosters. This finding is consistent with finding of study written by Cazares-Cervantes, LaGue \& Dykeman (2019). As the term implied, attitude markers allow writers to convey his position towards a certain proposition clearer. Several samples of attitude markers found in the data articles are provided in the followings:

(I-10) This is a sector that persistently becomes the source of systemic risk, namely the Asian financial crisis in 1998. (S14)

(I-11) It caused significant unrest in many of the financial and currency markets around the world. (S15)

(I-12) Iron toxicity Knowledge about eWOM communication against political brands will be beneficial for candidates to find effective and efficient political marketing communications. (S19)

(I-13) Iron toxicity is one of the important abiotic stresses that can decrease rice production. (H27)

(I-14) The application is flexible, especially in remote areas where there is no electricity grid, but renewable energy sources are abundant. (H30)

(I-15) Some studies (Thakor, 1996; Kashyap and Stein, 2000) explain how monetary policy affects the fluctuations in the growth of loans. (S29)

In the above sentences, attitude markers used are in the form of adjective, adverb, noun and verb. The attitude markers assist the writers to give tones to his statements. Sentences (1-10) and (1-11) show disapproval of the writer by using the word persistently. Sentences (1-12), (1-13), and (1-14) contains approval, while sentence (1-15) shows stance of neutral type.

\section{CONCLUSION}

The objectives of this study are to analyze the use of stance markers in social and hard science articles written by Indonesian. Using 16 journal articles as the data this research is able to find interesting findings. Based on the findings in this research it can be concluded that stance markers in the form of hedges, boosters, attitude markers and self-mentions are unemployed more by writers of social science articles compared to the hard science articles based. Among all the stance markers, modal verb will is the most frequently used hedge in the articles, while self-mention is the least stance marker used. The tone of stance can be observed through attitude markers selected. Stance markers representing approval, disapproval and neutral are found in the articles. It is suggested that the similar research with a bigger data can be conducted to have a more detailed explanation on the use of stance markers by Indonesian writers, especially in terms of the tone of the writers' stance.

\section{REFERENCES}

Aull, yL.L., \& Lamcaster, Z. 2014. Linguistic markers of stance in early and advanced academic writing a corpus-based comparison. Written Communication, 31(2), pp. 151-183 LIST OF

Bahrami, L., Dowlatabadi, H.R., Yazdani, H. \& American, M. (2018). Authorial Stance in Academic Writing: Issues and Implications for Research in English Language Teaching in International Journal of English \& Translation Studies. 6(2). 69-80

Biber, D \& Finegan, E. 1989. Styles of stance in English: Lexical and grammatical marking of evidentiality and affect in Text-interdisclipinary journal for the study of discourse, 9(1) pp.93124

Bermann, Ruth, Ragnarsdottir and Stromqvist, Sven. 2002. Discourse Stance: Written and and Spoken Languague in Written Language and Literacy. DOI: 10.1075/w11.5.2.06ber

Cazares-Cervantes, A., LaGue, A. \& Dykeman, Cass. 2019. Authorial Stance in Counselling Research Articles. http://psyarxiv.com/discover?q=authorial\%20stance\%20on\%20counseling 
Chindamo, M., Allwood, J., \& Ahlsen, Elisabeth. Some Suggestions for The Study of Stance in Communication. 2012. Privacy, Security, Risk and Trust (PASSAT), 2012 International Conference on and 2012 International Conference on Social Computing

Du Bois, \& John, W. 2007. The Stance Triangle in Stancetaking in Discourse. Amsterdam: John Benjamins Publishing Company

Farrokhi, Farahman \& Emami, Safoora. 2008. Hedges and Boosters in Academic Writing: Native vs Non-Native Research Articles in Applied Linguistics and Engineering

Hyland, Ken. 1998. Boosting, hedging and the negotiation of academic knowledge. in Text Interdisciplinary Journal for the Study of Discourse 18(3) January 1988. DOI: 10.1515/text.1.1998.18.3.349

Hyland, Ken. 2005. Stance and engangement: a model of interaction in academic discourse. London, Thousand Oaks, CA and New Delh: SAGE Publication

Mohammad Reza. Exploring Stance and Engagement Features in Discourse Analysis Papers in Theory and Practice in Language Studies, Vol 4, No 3, pp. 593-601, Finland: Academy Publisher

Salichah, Imraatu, Irawati Enny and Basthomi Yazid. 2015. Hedges and Boosters in Undergraduate Students' Research Articles in Jurnal Pendidikan Humaniora Vo. 3 No 2, pp. 154-160 June 2015. http://journal.um.ac.id/index.php/jph

Sanjaya, I.N.S., Sitawati, A.A.R., and Suciani, N.K. 2015. Comparing Hedges used by English and Indonesian Scholars in Published Research Articles: A Corpus-Based Study in TEFLIN Journal Vol 26, No 2 July 2015

Seyyedrezaie, Zari Sadat and Vahedi, Vahided Sadat. 2017. Projecting Gender Identity through metadiscourse marking: Investigating writer's stance taking in written discourse in Indonesian Journal of Applied Linguistics Vol 6, No 2(2017)

Tian, Xiufeng and Liang, Yueyuan. 2014.The Analysis of Writers Stance: A Comparison between Two Reviews on Desperate Housewives in Theory and Practice in Language Studies, Vol. 4, No.5, pp. 965-972, May 2014. Finland: Academy Publisher 
